\title{
Anti-Staphylococcus aureus Activity of Spouted Bed Dried and Freeze-Dried Powders of Pulp of Camu- Camu (Myrciaria dubia Mc. Vaugh)
}

\author{
Alice Fujita (I), Roberta Targino Correia (II), Bernadette Dora \\ Gombossy de Melo Franco (III), Genovese Maria Ines (I)
}

(I) USP - Laboratory of Food Bioactive Compounds (University of São Paulo, 05508-900 São Paulo SP, Brazil.), (II) UFRN - Laboratory of Food Bioactive Compounds and Dairy Technology, (Federal

University of Rio Grande do Norte, Campus Lagoa Nova, 59075-180 Natal - ), (III) USP - FCF Laboratory of Microbiology (University of São Paulo, 05508-900 São Paulo - SP, Brazil)

\section{Resumo}

Camu-camu (Myrciaria dubia Mc. Vaugh) is a native fruit mainly found in the Brazilian Northern Region. It is rich in bioactive compounds such as vitamin $\mathrm{C}$ and polyphenols. However, as this fruit is highly perishable, dehydrated fruit products might better allow its use as functional ingredients. The aim of this work was to evaluate the impact of spouted bed drying on bioactive compounds, and antioxidant and antimicrobial activities of dried camu-camu pulp compared to fresh and freeze-dried pulps. The bioactive value of the final dried products is also discussed. Frozen commercial camu-camu pulp was dried at selected temperatures (60 ${ }^{\circ} \mathrm{C}, 80{ }^{\circ} \mathrm{C}, 95^{\circ} \mathrm{C}$ and $110{ }^{\circ} \mathrm{C}$ ) with different maltodextrin concentrations $(0 \%, 3 \%$ and $6 \%)$, which was used as the carrier agent. The freeze-dried control sample was prepared at $-80^{\circ} \mathrm{C}$ for 120 hours. The fruit powders were studied in relation to ascorbic acid, total phenolics, proanthocyanidins contents and antimicrobial activity. Results showed that spouted bed process caused significant ( $p$ total phenolics $(33-42 \%)>$ proanthocyanidins $(16-18 \%)$. Maltodextrin may have protected the bioactive compounds, particularly proanthocyanidins. Freeze-drying better preserved antioxidant capacity (74 to $87 \%$ ) compared to spouted bed drying (29 to $78 \%$ ).Freeze-dried powder was classified as active, and spouted bed powders as partially active, against Staphylococcus aureus ATCC 2913. With the exception of powders with $6 \%$ of maltodextrin, all 
were more effective than ampicillin inhibition of this microorganism. Despite some loss of activity caused by drying, camu-camu powders remain excellent sources of bioactive compounds with great potential for use as new bioactive ingredients.

Palavras-Chave: antimicrobiano, antioxidante, compostos fenolicos Agência de Fomento: $\mathrm{CNPq}$ 